\title{
THE ASSESSMENT OF LIFE STYLE AND THE VISCERAL ADIPOSITY INDEX AS CARDIOMETABOLIC RISK FACTORS
}

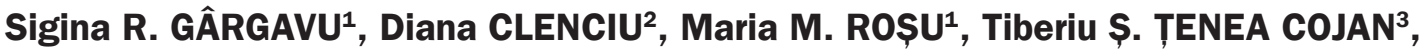 \\ Andrei COSTACHE ${ }^{1}$, Ionela M. VLADU ${ }^{3 \otimes}$, Maria MOȚA \\ ${ }^{1}$ The County Clinical Emergency Hospital of Craiova, Romania \\ ${ }^{2}$ The Municipal Hospital of Filantropia, Craiova, Romania \\ ${ }^{3}$ The University of Medicine and Pharmacy of Craiova, Romania
}

Received 05 Mar 2018, Accepted 14 May 2018

\section{Abstract}

Introduction. The patients with cardiometabolic/ cardiovascular risk are commonly found in clinics and ambulatory clinics. The cardiovascular (CV) or cardiometabolic (CM) risk factors and biomarkers are certain characteristics of the person without CV disease, which are independently correlated with the subsequent occurrence of $\mathrm{CV}$ disease, without necessarily having a causal relationship between factor and disease. The visceral adiposity index (VAI) indicates the function of visceral adipose tissue and its growth is independently correlated with cardiovascular and cerebrovascular risk.

The objective of the study was to evaluate the lifestyle and visceral adiposity index as possible cardiometabolic risk factors in patients with diabetes, prediabetes, and in the general population.

Methods. The study was epidemiological, transversal, noninterventional, and was performed by analyzing 300 subjects, divided into three groups: group 1 (100 patients with type 2 diabetes), group 2 (100 pre-diabetic patients), and group 3 (control) consisting of 100 individuals randomly recruited without diabetes.

Results. The accumulation of cardiovascular risk factors results is an increased risk of cardiovascular

\section{Résumé}

Lévaluation du style de vie et de l'indice d'adiposité viscérale en tant que facteurs de risque cardio-métaboliques

Introduction. Les patients présentant un risque cardio-métabolique/cardiovasculaire sont couramment rencontrés dans les cliniques et les cliniques ambulatoires. Les facteurs de risque cardiovasculaires/ cardio-métaboliques et les biomarqueurs sont des caractéristiques certaines de la personne sans maladie cardiovasculaire, qui sont corrélées de façon indépendante avec l'apparition ultérieure de la maladie $\mathrm{CV}$, sans nécessairement avoir une relation causale entre le facteur et la maladie. IAC indique la fonction du tissu adipeux viscéral et sa croissance est indépendamment corrélée avec le risque cardiovasculaire et cérébrovasculaire.

L'objectif de l'étude était d'évaluer le mode de vie et l'indice d'adiposité viscérale comme facteurs de risque cardio-métaboliques chez les patients diabétiques, prédiabétiques et dans la population générale. Méthodes. L'étude était épidémiologique, transversale, non interventionnelle, et a été réalisée en analysant 300 sujets, répartis en trois groupes: groupe 1 
disease. We found statistically significant differences between the three groups in terms of BMI, CT, VAI, CT, HDL-c and LDL-c values, which were higher in patients with diabetes mellitus (DM) than in prediabetics or in the general population, which also coincided with higher cardiovascular risk in these patients.

Conclusions. We emphasize the importance of both early cardiovascular risk assessment and the importance of controlling cardiovascular risk factors, both by non-pharmacological methods, and by associating early drug therapy when necessary.

Keywords: obesity, sedentariness, cardiovascular risk, diabetes, prediabetes.

\section{INTRODUCTION}

The patients with cardiometabolic (CM) or cardiovascular (CV) risk are commonly found in clinics and ambulatory clinics. The cardiovascular risk means the degree of risk for atherosclerotic cardiovascular pathology, predictable by quantifying the risk factors existing in each individual ${ }^{1}$. The cardiovascular or cardiometabolic risk factors (FR) and biomarkers are certain characteristics of the person without $\mathrm{CV}$ disease, which are independently correlated with the subsequent occurrence of $\mathrm{CV}$ disease, without necessarily having a causal relationship between factor and disease.

FR are divided into modifiable factors (controllable by therapeutic intervention) and non-modifiable. One of the modifiable risk factors is the pro-risk lifestyle defined by: smoking; sedentariness; high caloric diet (obesity), cholesterol and saturated AG, AG trans (proatherogenic, thrombogenic), hypersensitive (hypertensinogen), hyperuricemic-rich (red meat, viscera, glucose, fructose); low in fiber, vitamins, mineral salts and antioxidants; excess alcohol (over 30g/ day).

VAI indicates the function of visceral adipose tissue and its elevation is independently correlated with cardiovascular and cerebrovascular risk ${ }^{2}$.

The OBJective OF OUR STUDY was to evaluate the lifestyle and visceral adiposity index as possible cardiometabolic risk factors in patients with diabetes, pre-diabetes, and in the general population.
(100 patients atteints de diabète de type 2$)$, groupe 2 (100 patients prédiabétiques) et groupe 3 (témoin) de 100 personnes recrutées au hasard, sans diabète. Résultats. L'accumulation de facteurs de risque cardiovasculaires entraîne un risque accru de maladie cardiovasculaire. Nous avons trouvé des différences statistiquement significatives entre les trois groupes en termes d'IMC, CT, VAI, CT, HDL-c et LDL-c, qui étaient plus élevées chez les patients diabétiques que chez les prédiabétiques ou dans la population générale, qui a également coïncidé avec un risque cardiovasculaire plus élevé chez ces patients.

Conclusions. Nous insistons sur l'importance de l'évaluation précoce des risques cardiovasculaires et de l'importance de contrôler les facteurs de risque cardiovasculaires, tant par des méthodes non pharmacologiques, que par l'association d'une thérapie médicamenteuse précoce, si nécessaire.

Mots-clés: obésité, sédentarité, risque cardiovasculaire, diabète, prédiabète.

\section{Material AND Methods}

The study was epidemiological, transversal, noninterventional, and was performed by analyzing 300 subjects divided into three groups as follows:

- Group 1 including 100 patients with type 2 diabetes.

- Group 2 including 100 pre-diabetic patients.

- Group 3 (control) consisting of 100 individuals randomly recruited without diabetes.

The informed consent was signed by each participant in the study, in full knowledge, after having been informed of all relevant aspects in the decision-making process.

The study was conducted in accordance with ethical principles stemming from the Helsinki Declaration and is in line with the GCP and national and international regulations in force, respecting the right to integrity, confidentiality, and the option to withdraw the subject at any time from the study. All the activities of the research project were carried out in compliance with the legal norms.

Demographic data (age, gender, nationality, religion, marital status, study level, occupation), anthropometric data (weight, height, body mass index, waist circumference) were used and the following blood tests were performed: fasting blood glucose, total cholesterol, HDL-cholesterol, triglycerides.

The visceral adiposity index (VAI) was calculated according to gender by the following formulas: 


$$
\begin{array}{r}
\text { Males: } \mathrm{VAI}=\left(\frac{\mathrm{WC}}{39.68+(1.88 \times \mathrm{BMI})}\right) \times\left(\frac{\mathrm{TG}}{1.03}\right) \times\left(\frac{1.31}{\mathrm{HDL}}\right) \\
\text { Females: } \mathrm{VAI}=\left(\frac{\mathrm{WC}}{36.58+(1.89 \times \mathrm{BMI})}\right) \times\left(\frac{\mathrm{TG}}{0.81}\right) \times\left(\frac{1.52}{\mathrm{HDL}}\right) \\
\mathrm{VAI}=\text { visceral adiposity index, } \mathrm{WC}=\text { waist circumference, } \mathrm{BMI}=\text { body mass index. }
\end{array}
$$

The cardiovascular risk was assessed using the Framingham score. We have defined the ideal lifestyle using the following criteria:

1. Type of diet: weekly consumption of fatty/ lean meat; occasional consumption of saturated fats, occasional fast-food consumption, no excess salt; daily consumption of vegetables; daily fruit consumption.

2. Liquid consumption: daily water consumption over $1500 \mathrm{ml}$; occasional consumption of sweetened carbonated beverages.

3. Coffee consumption: occasionally or up to 2 cups / day.

4. Alcohol consumption: occasionally or daily $<200 \mathrm{ml}$.

5. Smoking: non-smoker or smoker.

6. Physical activity: average physical exercise; daily minimum 30 minutes walking or sports activities.

The patients were questioned by targeted questions about all 6 criteria. The data obtained were recorded as a Microsoft Excel spreadsheet and analyzed for each of the three batches using Microsoft Excel (Microsoft Corp., Redmond, WA, USA) together with XLSTAT 2014 for Microsoft Excel (Addinsoft SARL, Paris, France) and IBM SPSS Statistics 20.0 (IBM Corporation, Armonk, NY, USA) to analyze the relationships between clinical and paraclinical data of patients.

Data processing with lot descriptor analysis based on different parameters, as well as their graphical representation, was performed with Microsoft Excel, where we used the Functions-Statistical, Pivot Tables, Chart and Data Analysis menu functions.

\section{Results}

Each group comprised 100 patients equally divided by age and gender (1:1). The decades of age in which the patients of each lot were framed are represented in Table 1.

Table 1. The decades of age and sex distribution of the three groups.

\begin{tabular}{ccc}
\hline Decades & No. Males & No. Females \\
\hline $20-39$ years & $1(2 \%)$ & $1(2 \%)$ \\
\hline $40-59$ years & $17(34 \%)$ & $17(34 \%)$ \\
\hline $60-79$ years & $32(64 \%)$ & $32(64 \%)$ \\
\hline TOTAL & $50(100 \%)$ & $50(100 \%)$ \\
\hline
\end{tabular}

All the analyzed subjects were of Romanian nationality, of orthodox religion and came from the urban environment.

Over $65 \%$ of female subjects and over $80 \%$ of male subjects in each lot were married, respectively $68 \%$ vs $67.4 \%$ vs. $61.2 \%$ for women and $82 \%$ vs $84 \%$ vs $90 \%$ in the case of men.

Considering that the study was conducted in the urban environment, in all three groups, both male and female, there was an increased level of education among the subjects analyzed, over $70 \%$ of the women and over $85 \%$ of the men being graduates of vocational school, high school or higher education.

We found statistically significant differences between the three groups in terms of BMI, CT, VAI, CT, HDL-c and LDL-c values, which were higher in patients with diabetes mellitus (DM) than in prediabetics or in the general population, which also coincided with higher cardiovascular risk in these patients.

Most patients with cardiovascular risk were identified in the lot of patients with DM, $90 \%$ of whom had moderate to very high cardiovascular risk. Only $10 \%$ of patients with type 2 DM had no cardiovascular risk (Figure 1).

In the group of prediabetic patients, the cardiovascular risk was also significant, with approximately $80 \%$ of patients at moderate, high or very high risk (Figure 2).

In the third group of patients, the cardiovascular risk was the lowest, respectively in $36 \%$ of patients, as we expected, because this group included people without diabetes or prediabetes, a condition that, if present, places the patient in one category of cardiovascular risk (Figure 3).

We analyzed the lifestyle of patients in the three groups as a cardiometabolic modifiable risk factor.

The number of main meals/day - we found that both men and women served more than 3 main meals/day (63.3\% vs 72\%) in group 1 (diabetes) and in group 2 (prediabetes). We have applied statistical tests to identify a proportionality between the number of meals /day and the mean of VAI, and we obtained higher VAI values in prediabetic and diabetic patients who take $\geq 3$ main meals/day, but statistically insignificant $(p=0.646$, respectively $p=0,584)$. In the control group, the mean VAI was higher for 
Table 2. The characterization of the 3 groups according to the mean value of anthropometric, biochemical, systolic and diastolic blood pressure parameters.

\begin{tabular}{|c|c|c|c|c|}
\hline Variables & LOT & Media (SD) & $95 \% \mathrm{CI}$ & $p$ \\
\hline BMI & $\begin{array}{l}\text { LOT } 1 \\
\text { LOT } 2 \\
\text { LOT } 3\end{array}$ & $\begin{array}{l}31.43(6.15) \\
29.04(4.07) \\
27.82(4.71)\end{array}$ & $\begin{array}{l}30.216-32.658 \\
28.835-30.452 \\
26.886-28.756\end{array}$ & $<0,001$ \\
\hline WC & $\begin{array}{l}\text { LOT } 1 \\
\text { LOT } 2 \\
\text { LOT } 3\end{array}$ & $\begin{array}{c}105.99(12.15) \\
101.54(15.68) \\
96.74(12.05)\end{array}$ & $\begin{array}{c}103.586-108.408 \\
98.436-104.662 \\
94.352-99.136\end{array}$ & $<0,001$ \\
\hline VAI & $\begin{array}{l}\text { LOT } 1 \\
\text { LOT } 2 \\
\text { LOT } 3\end{array}$ & $\begin{array}{l}6.22(4.19) \\
4.99(4.04) \\
4.85(4.13)\end{array}$ & $\begin{array}{c}5.393-7.066 \\
4.182-5.805 \\
4.016-5.7\end{array}$ & 0,039 \\
\hline $\mathrm{TC}$ & $\begin{array}{l}\text { LOT } 1 \\
\text { LOT } 2 \\
\text { LOT } 3\end{array}$ & $\begin{array}{l}192.92(39.60) \\
219.63(54.75) \\
220.72(54.24)\end{array}$ & $\begin{array}{c}185.023-200.82 \\
208.675-230.631 \\
209.677-231.779\end{array}$ & $<0,001$ \\
\hline HDL-c & $\begin{array}{l}\text { LOT } 1 \\
\text { LOT } 2 \\
\text { LOT } 3\end{array}$ & $\begin{array}{l}49.32(12.54) \\
53.09(12.77) \\
56.82(18.76)\end{array}$ & $\begin{array}{l}46.82-51.82 \\
51.33-56.46 \\
52.99-60.64\end{array}$ & 0,002 \\
\hline LDL-c & $\begin{array}{l}\text { LOT } 1 \\
\text { LOT } 2 \\
\text { LOT } 3\end{array}$ & $\begin{array}{l}38.06(3.86) \\
49.09(4.98) \\
49.06(5.08)\end{array}$ & $\begin{array}{l}104.15-119.50 \\
127.56-147.34 \\
136.50-146.71\end{array}$ & $<0,001$ \\
\hline TG & $\begin{array}{l}\text { LOT } 1 \\
\text { LOT } 2 \\
\text { LOT } 3\end{array}$ & $\begin{array}{c}79(7.49) \\
83.33(8.41) \\
95.72(9.82)\end{array}$ & $\begin{array}{l}143.02-174.53 \\
124.40-157.81 \\
121.38-160.38\end{array}$ & 0,250 \\
\hline Systolic blood pressure & $\begin{array}{l}\text { LOT } 1 \\
\text { LOT } 2 \\
\text { LOT } 3\end{array}$ & $\begin{array}{l}19.61(1.97) \\
39.97(3.99) \\
20.22(2.03)\end{array}$ & $\begin{array}{l}135.26-143.75 \\
134.26-150.12 \\
135.95-144.01\end{array}$ & 0,806 \\
\hline Diastolic blood pressure & $\begin{array}{l}\text { LOT } 1 \\
\text { LOT } 2 \\
\text { LOT } 3\end{array}$ & $\begin{array}{l}10.48(1.05) \\
13.83(1.38) \\
10.13(1.01)\end{array}$ & $\begin{array}{l}77.45-81.64 \\
77.16-82.65 \\
78.92-82.96\end{array}$ & 0,680 \\
\hline
\end{tabular}

$B M I=$ body mass index, $\mathrm{WC}=$ waist circumference, $\mathrm{VAI}=$ visceral adiposity index, $\mathrm{TC}=$ total - cholesterol, $\mathrm{HDL}=$ high density lipoproteins, $\mathrm{LDL}=$ low density lipoproteins

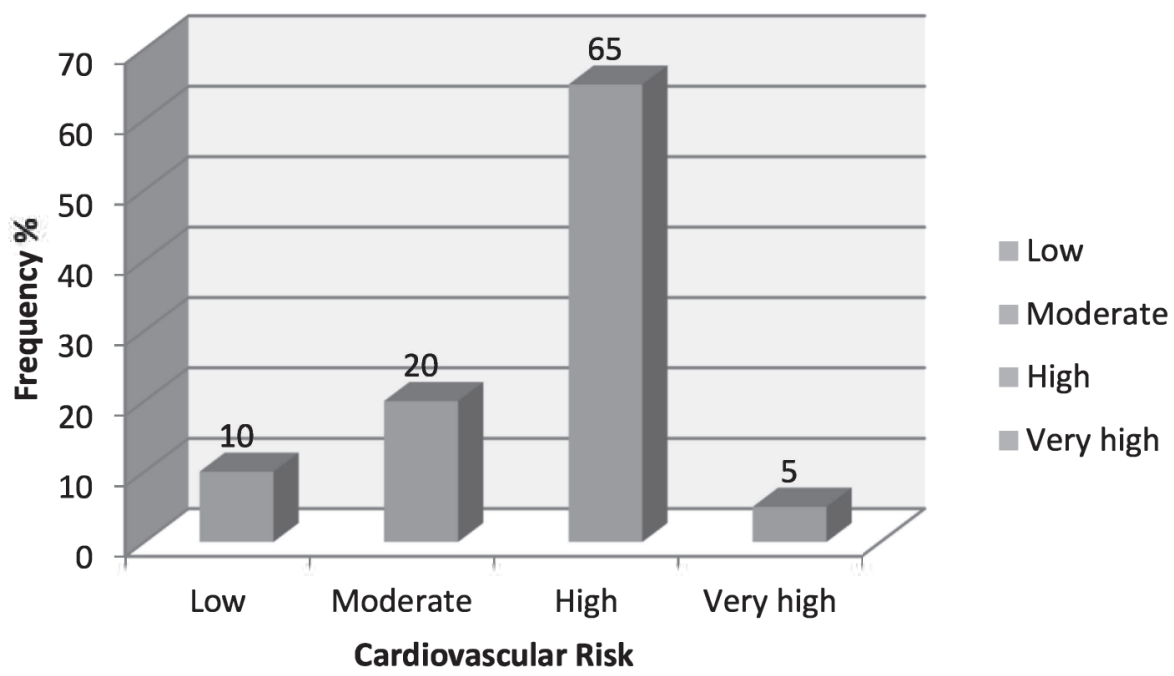

Figure 1. The cardiovascular risk in patients with type 2 DM (group 1) 


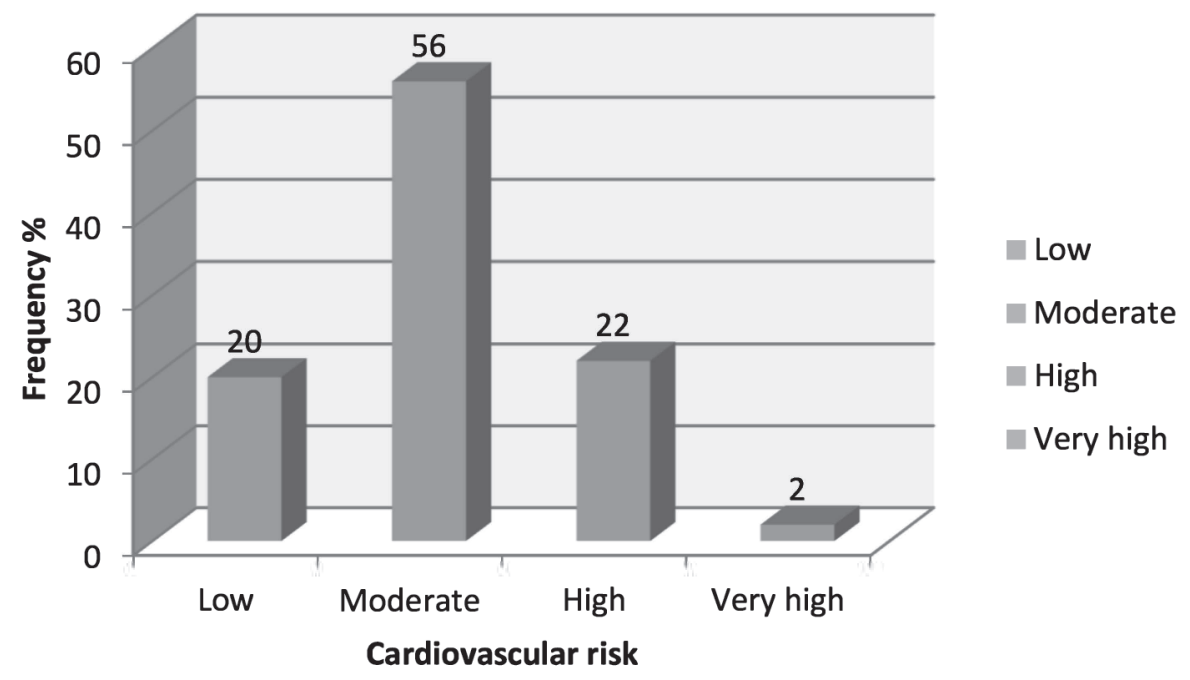

Figure 2. The cardiovascular risk in patients with prediabetes (group 2)

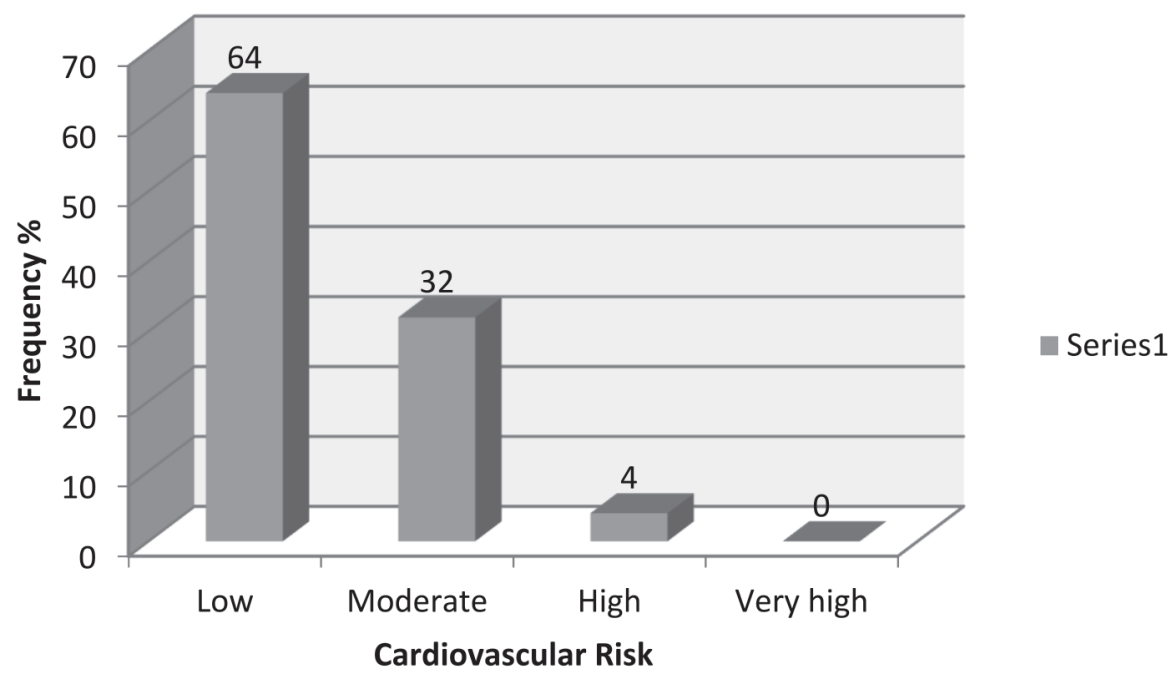

Figure 3. The cardiovascular risk in the general population (group 3)

those who consumed $<3$ main meals/day, but no significant statistical differences were found in this case $(\mathrm{p}=0,237)$.

\section{Daily consumption of fruits, vegetables and sweets}

In a high percentage, both women and men with diabetes and prediabetes consume fruits and vegetables daily ( $88 \%$ vs $94 \%$ ) and do not consume daily sweets. The same was found in subjects in the control group (without prediabetes/diabetes), however there was a statistically significant difference $(p=0,014)$ between the three groups in the case of women.

The statistical analysis of daily consumption of vegetables and fruits compared to the mean value of VAI has identified higher values for prediabetic and diabetic patients who do not consume fruits and vegetables daily, but the differences were statistically insignificant $(p=0,118$ and $p=0,762)$. In the case of the control lot, the situation was reversed, meaning that higher mean of VAI values were found in people who consume fruits and vegetables daily, but also the differences were statistically insignificant $(p=0,225)$.

As a result of the statistical analysis of the daily consumption of sweets, we noted that the average VAI value is higher for those who do not eat sweets in all three groups, but the differences between them are statistically insignificant $(\mathrm{p}=0,392 ; \mathrm{p}=0,629 ; \mathrm{p}=0,5)$.

Daily consumption of alcohol was significantly higher among men $(p=0.047)$ in the control group compared to those in the prediabetes and diabetes 
group. Although all men consume more alcohol per day than women, consumption is lower than in men from the control group, due to the lifestyle optimization measures adopted after diagnosis with prediabetes or diabetes.

The mean VAI was higher in people who consume alcohol daily in the control group and in the prediabetic group, but statistically insignificant in none of the groups $(p=0,921$ and $p=0,638)$.

In the diabetic group, the mean VAI was higher in those who did not consume alcohol daily, but also statistically insignificant $(\mathrm{p}=0,44)$.

\section{Smoking}

Both women and men were registered in all three groups, with more non-smokers than smokers.

Of those who smoked, there were more males than females, with significant percentage differences between them in the diabetes group and the control group ( $46 \%$ vs. $28 \%$, respectively $36 \%$ vs. $14 \%$ ), but no statistically significant differences between the groups $(\mathrm{p}>0.05)$.

Also, there were no statistically significant differences between women and men in the number of cigarettes smoked daily $(p=0,953)$, over $80 \%$ stating that they smoked 10-20 cigarettes / day.

The percentage of former smokers was higher among males, but there was no significant difference between the three groups $(p=0,329)$.

The mean VAI is not influenced by the smoker or non-smoker status in control and prediabetic patients. In the diabetic group, the mean value of VAI is higher for former smokers than for smokers/ non-smokers, the difference between them being statistically significant $(\mathrm{p}=0,014)$.

Regarding sleep, analyzed as a component of lifestyle, we found that both women and men of the three groups slept over 6 hours/day, with a statistically higher percentage being recorded in each lot in men compared with women ( $72 \%$ vs. $52 \%, 74 \%$ vs $58 \%$, respectively $80 \%$ vs $66 \%$ ).

In the prediabetic group, mean VAI was higher in those who sleep less than 6 hours/day, but statistically insignificant $(p=0.79)$, in the control and diabetic groups, the mean of VAI being higher in those who sleep more than 6 hours/day, but still insignificant statistically $(\mathrm{p}=0,313$, respectively $\mathrm{p}=0,237)$.

Regarding physical activity, there were no significant differences between the three groups and between men and women, more than $70 \%$ of subjects underwent physical activity, walking at least 30 minutes / day, more than 4 times / week.

The mean VAI was higher in those with diabetes who performed physical activity more than 4 times/ week, but not statistically significant.

\section{Discussion}

More and more data support the relationship between the factors that come from the modern living environment and health. These factors can be found in the lifestyle of modern humans and are associated with increased prevalence of chronic diseases: obesity, metabolic syndrome, DM, dyslipidemia, arterial hypertension, cardiovascular disease, some cancers, musculoskeletal disorders, neuropsychiatric disorders with important consequences on health and financial status ${ }^{3-7}$.

Although all of the negative lifestyle factors are important, our study focused primarily on unhealthy eating and sedentariness, because it is the main cause of the dramatic increase in the incidence of obesity and type $2 \mathrm{DM}$. Epidemiological data show that the occurrence of these diseases is inversely associated with the degree of physical activity. Obesity and, in particular, abdominal obesity is a complex and aggressive form of disease, with a huge potential for cardiovascular and metabolic diseases, associating with lipid profile deterioration, glucose metabolic abnormalities and concomitant hypertension ${ }^{8-11}$.

As a result of the above, two out of three Romanian people have cardiovascular disease, as opposed to the developed countries of Western Europe, where the proportion of cardiovascular disease mortality is 1 to 3 , which can be explained by the prevention activity of these risk factors and the awareness of the seriousness of the risk of not being treated, topics that have been brought to public attention for decades in these countries ${ }^{12,13}$.

Low level of training is also a cardiovascular risk factor, both by decreasing treatment compliance and by low awareness of cardiovascular risk factors. Sedentariness predisposes to cardiovascular disease by increasing the incidence of obesity, decreasing insulin sensitivity and increasing blood pressure ${ }^{14}$. In our study, sedentariness was an important cardiovascular risk factor, with the percentage of sedentary patients with cardiovascular risk being higher compared to those at risk or lower cardiovascular risk. Sedentariness increases the risk of death by cardiovascular disease in men by $52 \%$ and in women by $28 \%$. Compared to the European average of $27 \%$, only $19 \%$ of the Romanian people are constantly making physical effort ${ }^{12}$.

Inappropriate food-based foods with high saturated fat content predispose to obesity. In our study, excess consumption of saturated fats of animal origin was an important cardiovascular risk factor; the proportion of patients consuming saturated fat in excess among subjects with cardiovascular risk was higher compared to those at risk.

Smoking is an important risk factor that increases the incidence of cardiovascular disease by 4 times and cardiovascular disease mortality 2-3 times over non-smokers ${ }^{15}$. Also, in our study, smoking was an 
important cardiovascular risk factor and the percentage of smokers in those with cardiovascular risk was higher compared to those at risk.

Quitting smoking reduces cardiovascular risk as early as the first day, so one year after smoking cessation, the risk of heart attack is halved, and after 15 years it gets to the level of a non-smoker ${ }^{15}$.

Alcohol consumed in large quantities has the effect of increasing blood pressure. In our study, excess alcohol consumption was an important cardiovascular risk factor and the proportion of patients consuming excess alcohol in the group of subjects with cardiovascular risk was higher compared to those at risk. Each glass of alcohol adds 70-100 calories, with weight gain, so that daily alcohol consumption should be limited to $30 \mathrm{ml}^{15}$. The moderate consumption of red wine daily, that is, a glass for women and a maximum of two glasses for men, has a favorable effect on the cardiovascular system. This beneficial role is due to the presence in red wine of resveratrol, which has a strong antioxidant effect, inhibiting lipid peroxidation of low density (LDL), anti-inflammatory by inhibiting cyclooxygenase and decreasing the synthesis of pro-inflammatory prostaglandins, platelet anti-aggregates and nitric oxide production stimulation and releasing it at the endothelial level ${ }^{16}$.

\section{Conclusions}

It is very important for the population to be aware of the danger posed by all these risk factors in the context of the atherosclerotic process, to adopt a healthy lifestyle, to carry out regularly an assessment of the state of health and, when it is necessary, to apply a treatment that reduces to as low as possible all these risk factors. In Romania, due to the aging of the population and the inadequate lifestyle, the share of cardiovascular risk factors in the general population has increased recently, leading to an increased incidence of cardiovascular disease. The accumulation of cardiovascular risk factors results in an increased risk of cardiovascular disease.

We emphasize the importance of both early cardiovascular risk assessment and the importance of controlling cardiovascular risk factors, both by non-pharmacological methods and by associating early drug therapy, when necessary.

\section{Acknowledgement}

All the authors contributed equally to this study and they all have the same rights.

\section{Compliance with Ethics Requirements:}

„The authors declare no conflict of interest regarding this article"
„The authors declare that all the procedures and experiments of this study respect the ethical standards in the Helsinki Declaration of 1975, as revised in 2008(5), as well as the national law. Informed consent was obtained from all the patients included in the study"

\section{References}

1. Maria Moța. Diabet zaharat, nutriție, boli metabolice. Ed. Medicală Universitară Craiova, 2002.

2. Amato MC, Giordano C, Galia M, et al. AlkaMeSy Study Group: Visceral Adiposity Index: a reliable indicator of visceral fat function associated with cardiometabolic risk. Diabetes Care 2010, 33:920-922.

3. Rădulescu D, Balcangiu Stroescu A, et al. Vitamin K influence on cardiovascular mortality in chronic hemodialysed patients. Revista de Chimie, 2017, 68(1):52-54.

4. Checheriță IA, Smarandache D, Rădulescu D, et al. Calcific uremic arteriolopathy in hemodialyzed patients. Chirurgia (Bucur). 2013;108(5):736-40.

5. Niculae A, Peride I, Marinescu-Paninopol A, et al. Renal artery bilateral arteriosclerosis cause of resistant hypertension in hemodialysed patients. Rom J Morphol Embryol. 2016;57(2):591-4.

6. Socea B, Nica AA, Smaranda CA, et al. Solitary cecum diverticulitis - a surprising diagnosis. Archives of the Balkan Medical Union, 2017; 52 (4):467-470.

7. Niculae A, Peride I, Vinereanu V, et al. Nephrotic syndrome secondary to amyloidosis in a patient with monoclonal gammopathy with renal significance (MGRS). Rom J Morphol Embryol. 2017;58(3).

8. Iancu MA, Balta MD, Bejan CG, et al. Consequences of obesity at the menopause. Practica Medicala, 2018;1(54):25-28.

9. Diaconu C, Dediu G. Sleep apnea syndrome and cardiovascular risk. Archives of the Balkan Medical Union, 2016;51(2):205-208.

10. Diaconu C, Dediu G. Obesity-related comorbidities: one actress, multiple scenes. Medicina Modernă, 2016, 23(1):12-15

11. Diaconu C, Paraschiv B. Clinical characteristics of obese patients with hypertension and ischemic heart disease. Romanian Journal of Internal Medicine 2014, 52(4):251-255.

12. Cinteză M, Pana B, Cochino E, et al. Prevalence and control of cardiovascular risk factors in Romania: Cardio-zone national study. Mædica - A Journal of Clinical Medicine, 2007, 2(4): 277-288.

13. Ezzati M, Lopez AD, Rodgers A, Vander Hoorn S, Murray CJ. Comparative Risk Assessment Collaborating Group. Selected major risk factors and global and regional burden of disease. Lancet 2002; 360: 1347-1360.

14. Lakka HM, Laaksonen DE, Lakka TA, et al. The metabolic syndrome and total cardio-vascular disease mortality în middle aged men. JAMA 2002;288:2709-2716.

15. Yusuf S, Reddy S, Ounpuu S, et al. Global burden of cardiovascular diseases: part I: general considerations, the epidemiologic transition, risk factors, and impact of urbanization. Circulation 2001; 104:2746-2753.

16. Harati H, Hadaegh F, Momenan AA, et al. Reduction in incidence of type 2 diabetes by lifestyle intervention in a middle eastern community. Am J Prev Med. 2010, 38: 628-636. e621, 10.1016. 